\title{
Extraction-Spectrophotometric Determination of Berberine in Crude Drugs by the Formation of a New Ion Associate
}

\author{
Tadao SakaI, Noriko Ohno, Hideto SaSaki and Teruyuki Hyuga \\ Department of Chemistry, Asahi University, Hozumi, Gifu 501-02, Japan
}

\begin{abstract}
A sensitive and selective method based on the formation of ternary complexes of berberine, quinidine and a divalent anion of dibasic acid dyes $\left(A^{2-}\right)$ such as Bromophenol Blue, Bromochlorophenol Blue and Bromocresol Green is described. Berberine was extracted in large amounts into 1,2-dichloroethane with $\mathrm{A}^{2-}$; only in the presence of quinidine in a neutral aqueous media. Berberine could react in 1,2-dichloroethane with $\mathrm{A}^{2-}$ to give a blue product. In addition, the extractability of berberine in a neutral aqueous media could be enhanced by the formation of bulky ternary complexes (berberine ${ }^{+}-\mathrm{A}^{2-}$-quinidine ${ }^{+}$); the selectivity was improved because most of the amines and alkaloids did not react with $\mathrm{A}^{2-}$ in the above-mentioned media. The blue complexes can be used for a sensitive and selective spectrophotometric determination of berberine in crude drugs.
\end{abstract}

Keywords Berberine determination, quinidine, Bromophenol Blue, Bromochlorophenol Blue, Bromocresol Green, ternary complex, spectrophotometry

Most methods for extraction-spectrophotometric determinations of quaternary ammonium salts are based on the formation of ion associates with anionic dyes. Although the triphenylmethane series and azo dyes, such as Bromophenol Blue (BPB) ${ }^{1,2}$ and Orange $\mathrm{II}^{3}$, have been used for the selective determination of quaternary ammonium salts by solvent extraction, the color development and extractability of ion associates were not satisfactory. For instance, the calibration graphs for quaternary ammonium ions using a BPB-1,2-dichloroethane extraction system did not pass through the origin, and the extractability of the associates decreased considerably in the lower concentration range. Of the triphenylmethane dyes investigated, tetrabromophenolphthalein ethyl ester (TBPE) was excellent for the determination of trace amounts of quaternary ammonium salts, and their molar absorptivities were about $9.5 \times 10^{4} \mathrm{~mol}^{-1} \mathrm{~cm}^{-1}{ }^{4}$ However, TBPE has a disadvantage regarding selectivity. ${ }^{5}$ In a previous paper ${ }^{6}$ the author (T.S.) stated that although the BPB- $\mathrm{R}_{4} \mathrm{~N}^{+}$ associate could not be extracted in the absence of quinine from a neutral media, trace amounts of quaternary ammonium salts $\left(\mathbf{R}_{\mathbf{4}} \mathrm{N}^{+}\right)$could be successfully co-extracted with BPB into chloroform to form a ternary complex, BPB-quinine- $\mathrm{R}_{4} \mathrm{~N}^{+}$. In the extraction system both the extractability and selectivity for quaternary ammonium salts were enhanced.

The present paper concerns berberine, an alkaloid which could be successfully and selectively extracted with divalent dyestuffs $\left(\mathrm{A}^{2-}\right)$ into 1,2-dichloroethane in a slightly alkaline media, though only in the presence of quinidine, which has a higher $\mathrm{p} K$ than does quinine. Berberine can be determined spectrophotometrically without any interference from various amines and alkaloids.

\section{Experimental}

\section{Apparatus}

A Shimadzu (Model UV-260) double-beam spectrophotometer with stoppered glass cells of $10-\mathrm{mm}$ path length was used for recording the spectra and making absorbance measurements. A Toa-Dempa (Model HM5B) $\mathrm{pH}$ meter equipped with a glass electrode was used to measure the $\mathrm{pH}$ of the aqueous phases after extraction. Extractions were carried out by shaking with an Iwaki (Model KM) shaker. Centrifugation was performed with a Kubota (KS-4000) centrifuge.

\section{Reagents \\ All reagents used were of analytical-reagent grade.} Standard berberine solution. A stock solution of $1 \times 10^{-3} \mathrm{M}\left(\mathrm{M}=\mathrm{mol} \mathrm{dm}^{-3}\right)$ berberine was prepared by dissolving $0.4078 \mathrm{~g}$ of berberine hydrochloride (dried at $105^{\circ} \mathrm{C}$ ) in hot distilled water and diluting to 11 with distilled water. The stock solution was standardized by the official method. ${ }^{7}$

Quinidine solution. A stock solution of $2 \times 10^{-2} \mathrm{M}$ was prepared by dissolving $0.783 \mathrm{~g}$ of quinidine sulfate (Merck) in distilled water and diluting to $100 \mathrm{ml}$.

Palmatine and coptidine solutions. Appropriate amounts of palmatine methylsulfate (purchased from Dainippon Pharmaceutical Co., Osaka) and coptidine chloride (purchased from Yoneyama Yakuhin Co., Osaka) were dissolved in distilled water to make $10^{-3} \mathrm{M}$ 
Table I Conditions used here for the determination of berberine with dyestuffs

\begin{tabular}{lccc}
\hline Dye & BCPB & BCG & TBPB \\
Added conc. & $1 \mathrm{ml}, 1 \times 10^{-3} \mathrm{M}$ & $1 \mathrm{ml}, 6 \times 10^{-4} \mathrm{M}$ & $1 \mathrm{ml}, 1.5 \times 10^{-3} \mathrm{M}$ \\
Final conc. & $2 \times 10^{-5} \mathrm{M}$ & $1.2 \times 10^{-5} \mathrm{M}$ & $3 \times 10^{-5} \mathrm{M}$ \\
$\mathrm{pH}$ & 8.2 & 8.5 & 10 \\
$\lambda_{\max }$ & $605 \mathrm{~nm}$ & $633 \mathrm{~nm}$ & $625 \mathrm{~nm}$ \\
Added Qd conc. & $2 \mathrm{ml}, 2 \times 10^{-3} \mathrm{M}$ & $1.5 \mathrm{ml}, 2 \times 10^{-3} \mathrm{M}$ & $1 \mathrm{ml}, 1 \times 10^{-2} \mathrm{M}$ \\
Final conc. & $8 \times 10^{-5} \mathrm{M}$ & $6 \times 10^{-5} \mathrm{M}$ & $2 \times 10^{-4} \mathrm{M}$ \\
\hline
\end{tabular}

Qd: quinidine solution.

solutions.

Working solutions were prepared by accurate dilution of the above-mentioned solutions.

Dyestuff solutions. Bromophenol Blue (BPB), Bromochlorophenol Blue (BCPB), Bromocresol Green (BCG) and Tetrabromophenol Blue (TBPB) were prepared by dissolving a proper amount of BPB, BCPB, BCG and TBPB in $100 \mathrm{ml}$ of ethanol.

Borate-phosphate buffer solutions were made from equal volumes of $0.3 \mathrm{M}$ potassium dihydrogen phosphate and $0.1 \mathrm{M}$ sodium borate; the pHs were then adjusted with $1 \mathrm{M}$ sodium hydroxide and $0.5 \mathrm{M}$ sulfuric acid.

1,2-Dichloroethane was used without further purification.

\section{Standard procedure}

Put $0.5-2.5 \mathrm{ml}$ of berberine standard solution $\left(1 \times 10^{-4}\right.$ $\mathrm{M}), 1 \mathrm{ml}$ of $1.2 \times 10^{-3} \mathrm{M}$ quinidine, $1 \mathrm{ml}$ of $1.5 \times 10^{-3} \mathrm{M}$ BPB and $10 \mathrm{ml}$ of borate-phosphate buffer solution (pH 7.75) into a 50-ml calibrated flask. Dilute the mixture with distilled water to $50 \mathrm{ml}$. Transfer the mixture into a $100-\mathrm{ml}$ separating funnel and shake with $10 \mathrm{ml}$ of 1,2-dichloroethane for $5 \mathrm{~min}$ mechanically. Then centrifuge to remove water droplets. After separation of the organic layer, measure the absorbance of the organic phase at $605 \mathrm{~nm}$ against a reagent blank. The conditions for other extraction systems are shown in Table 1.

\section{Results and Discussion}

\section{Absorption spectra}

Figures 1 and 2 show the absorption spectra of the complexes formed from onium compounds and dyestuffs. In the extraction system with BPB (Fig. 1), the BPB-quinidine associate (curve 1) shows a red color with a maximum absorption wavelength at $580 \mathrm{~nm}$. The absorption maximum of the BPB-berberine associate was at $605 \mathrm{~nm}$, though the extractability of the associate from the neutral media was poor (curve 2). However, a trace amount of berberine was extracted into 1,2dichloroethane, even from the above-mentioned $\mathrm{pH}$ media, only in the presence of an adequate amount of quinidine. The extractability was greatly enhanced and the absorption maximum shifted to $605 \mathrm{~nm}$ (curve 3).

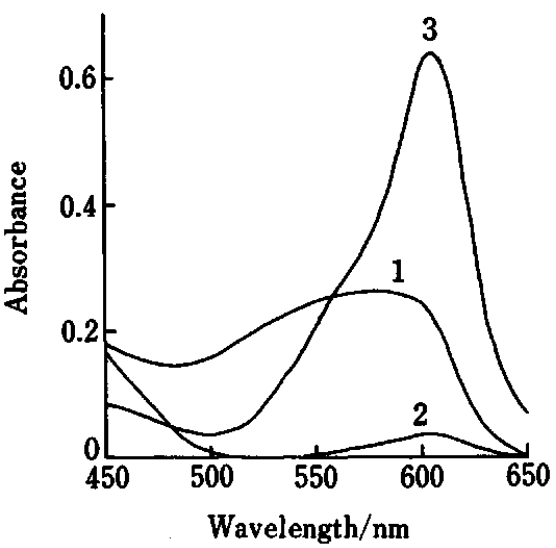

Fig. 1 Absorption spectra of ion associates with BPB. 1: BPB-quinidine associate; 2: BPB-berberine associate, reference: 1,2-dichloroethane; 3: BPB-quinidine-berberine associate, reference: reagent blank, $\mathrm{pH}: 7.75, \mathrm{BPB}: 3 \times 10^{-5} \mathrm{M}$, quinidine: $2.4 \times 10^{-5} \mathrm{M}$, berberine: $2 \times 10^{-6} \mathrm{M}$.

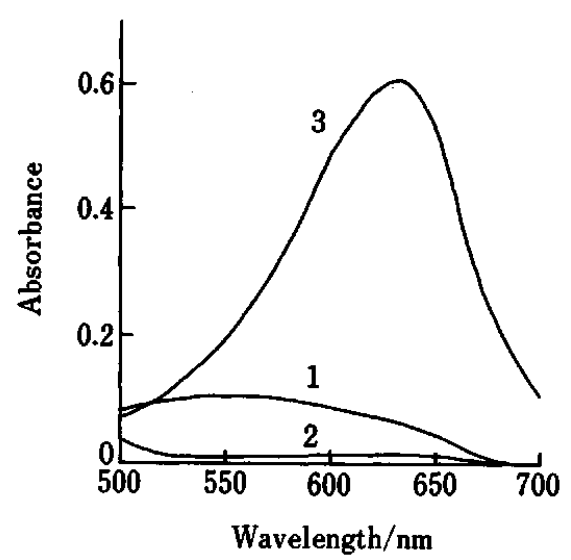

Fig. 2 Absorption spectra of ion associates with BCG. 1: BCG-quinidine associate; 2: BCG-berberine associate, reference: 1,2-dichloroethane; 3: BCG-quinidine-berberine associate, reference: reagent blank, $\mathrm{pH}: 8.5, \mathrm{BCG}: 1.2 \times 10^{-5} \mathrm{M}$, quinidine: $6 \times 10^{-5} \mathrm{M}$, berberine: $4 \times 10^{-6} \mathrm{M}$.

On the other hand, in the extraction system with BCG (Fig. 2), the BCG-quinidine associate at $\mathrm{pH} 8.5$ showed a maximum absorption wavelength at $550 \mathrm{~nm}$ (curve 1) and that of BCG-berberine at $633 \mathrm{~nm}$ (curve 2), although its extractability was extremely poor. In the presence of 
an appropriate amount of quinidine, however, berberine was co-extracted with BCG into 1,2-dichloroethane, similar to the BPB extraction system (curve 3 ). The wavelength shift was very large compared with that of the ternary complexes with BPB. It is assumed that the formation of charge transfer complexes by a hydrogen bridge between protonated quinidine $\left(\mathrm{H}^{+}-\mathrm{NQd}\right)$ and phenolic $\mathrm{O}^{-}$-group of $\mathrm{BCG}$ was considerable and characteristic compared with that of BPB.

\section{Effect of $p H$ on extraction of ion associates with dyestuffs}

The effect of $\mathrm{pH}$ on the $\mathrm{A}^{2-}$-quinidine, $\mathrm{A}^{2-}$-berberine and $\mathrm{A}^{2-}$-quinidine-berberine ion associates was examined by adding various buffered solutions. The obtained results using a TBPB dye anion are shown in Fig. 3. The TBPB-quinidine associate (curve 1) had an optimum pH at 7.5 , and the range in which the difinite chemical species could be obtained was found to be very narrow.

However, the $\mathrm{pH}$ region for TBPB-berberine associates was wide (curve 2) and the extractability was good compared with other $\mathbf{A}^{2-}$-berberine associates, although the extraction percentage was not proportional to the concentration of berberine at low concentrations. On the other hand, the formation of ternary complexes

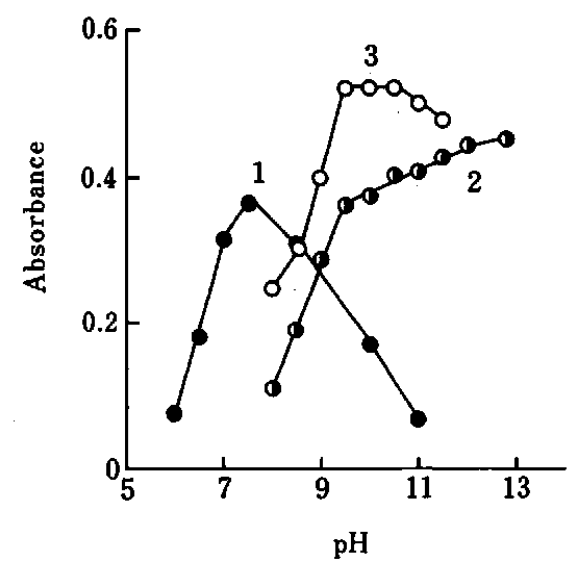

Fig. 3 Effect of $\mathrm{pH}$ on the formation of ion associates with TBPB. 1: TBPB-quinidine associate; 2: TBPB-berberine associate, reference: 1,2-dichloroethane; 3: TBPB-quinidineberberine associate, reference: reagent blank, wavelength: $625 \mathrm{~nm}$, TBPB: $3 \times 10^{-5} \mathrm{M}$, quinidine: $2 \times 10^{-4} \mathrm{M}$, berberine: $3 \times 10^{-6} \mathrm{M}$.

Table 2 Comparison of optimum $\mathrm{pH}$ ranges with $\mathrm{A}^{2-}$ berberine-quinine and/or -quinidine

\begin{tabular}{lccc}
\hline Dyestuff & $\mathrm{p} K$ & \multicolumn{2}{c}{ Optimum $\mathrm{pH}$ range } \\
& & $(\mathrm{p} K 4.1,8.0)$ & Quinine \\
& 3.8 & $6.5-7.1$ & $7.3-7.9$ \\
BPB & 4.1 & $6.3-6.9$ & $7.7-8.3$ \\
BCPB & 4.6 & $7.9-8.5$ & $7.7-8.7$ \\
BCG & 3.8 & $8.6-9.1$ & $9.5-10.5$ \\
\hline
\end{tabular}

(berberine-TBPB-quinidine) showed an intermediate $\mathrm{pH}$ region between those of TBPB-quinidine and TBPBberberine associates (curve 3 ). Accordingly, the $\mathbf{p H}$ dependency on ion-pair extraction with dibasic acid dyes was improved by the formation of new ion associates. In the TBPB extraction system, extraction was carried out at $\mathrm{pH}$ 10. Table 2 shows a comparison of the optimum $\mathrm{pH}$ ranges with $\mathrm{A}^{2-}$-berberine-quinine and/or -quinidine associates. It was found that the optimum $\mathrm{pH}$ region with quinidine is in a more alkaline media, compared with that of quinine. The formation of ternary complexes in more alkaline media has the advantage to eliminate interference from both amines and alkaloids. As a result, quinidine was chosen for the selective determination of berberine in crude drugs.

\section{Effect of quinidine concentration}

The effect of varying the quinidine concentration on the extraction of ion associates with $\mathrm{A}^{2-}$ was examined. As shown in Fig. 4, the absorption of the ternary complexes increased with increasing the quinidine concentration, and reached a constant value at $2 \times 10^{-5} \mathrm{M}$ quinidine in the BPB extraction system. However, the larger was the quinidine concentration, the larger was the absorption of the reagent blank. Accordingly, the quinidine concentration that gives a constant, smaller reagent blank absorption should be recommended. In the BPB extraction system, though $2.4 \times 10^{-5} \mathrm{M}$ of quinidine was used, the concentrations of quinidine in other extraction systems are shown in Table 1.

\section{Effect of dyestuff concentrations}

While keeping the quinidine concentration constant, the dyestuff concentrations were varied in order to examine the effect on the formation of ternary complexes. In general, an increase in the dyestuff concentrations gave a higher absorbance of the reagent blank, although the absorbances of ternary ion associates were constant. In both BPB and TBPB extraction systems, however, the larger were the dyestuff concen-

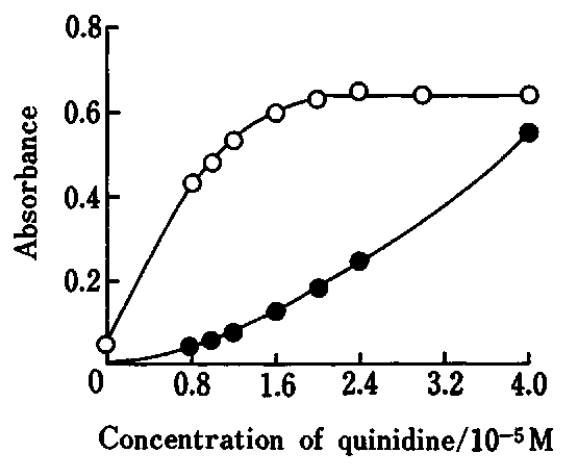

Fig. 4 Effect of quinidine concentration on the formation of ion associates with BPB. 1: BPB-quinidine associate, reference: 1,2-dichloroethane; 2: BPB-quinidine-berberine associate, reference: reagent blank, wavelength: $605 \mathrm{~nm}$, $\mathrm{pH}: 7.75, \mathrm{BPB}: 3 \times 10^{-5} \mathrm{M}$. 
trations, the smaller was the formation of ternary ion associates. This was because the extractability of BPB (TBPB)-quinidine associates was irregularly accelerated by increasing the dyestuff concentrations.

\section{Extracting solvents}

Berberine with $\mathrm{A}^{2-}$-quinidine was successfully extracted into organic solvents. Seven solvents such as nitrobenzene (high dielectric constant), dichloromethane, 1,2dichloroethane, o-dichlorobenzene (intermediate dielectric constant), chlorobenzene and chloroform (low dielectric constant) were examined in the extraction system described above. Of these solvents, dichloromethane, 1,2-dichloroethane, o-dichlorobenzene and chloroform showed higher absorbances. However, 1,2dichloroethane was the best regarding color stability of the organic phase and reproducibility upon extraction. Although nitrobenzene gave a high extraction percentage, the absorbance difference between $\mathrm{A}^{2-}$-quinidine and $\mathrm{A}^{2-}$-quinidine-berberine associates was small and, moreover, $\lambda_{\max }$ for both associates appeared at the same wavelength. This was because of ion-pair formation, not charge transfer complexes in nitrobenzene.

It is consequently assumed that a quinidine cation in the $\mathrm{A}^{2-}$ (quinidine) ${ }_{2}$ associate is smoothly and easily replaced by a berberine cation to form new ion associates, $\mathrm{A}^{2-}$-quinidine-berberine, in the intermediate solvents. The extraction equilibria are given in Eqs. (1) and (2):

$$
\left.\mathrm{A}_{\mathrm{w}}^{2-}+2 \text { quinidine } \mathrm{w}_{\mathrm{w}}^{+} \rightleftharpoons \mathrm{A}^{2-} \cdot \text { (quinidine }^{+}\right)_{2, \mathrm{o}}
$$

and

$$
\begin{aligned}
& \mathrm{A}^{2-} \cdot(\text { quinidine })_{2, \mathrm{o}}+\text { berberine }_{\mathrm{w}}^{+} \\
& \rightleftharpoons\left(\mathrm{A}^{2-} \cdot \text { quinidine }{ }^{+}\right)^{-} \cdot \text { berberine }_{\mathrm{o}}^{+}+\text {quinidine } \mathrm{w}_{\mathrm{w}}^{+}
\end{aligned}
$$

Here, subscripts $w$ and $o$ refer to the aqueous and organic phases, respectively.

\section{Calibration graphs and molar absorptivities}

The calibration graphs obtained by the standard procedure, with the reagent blank used as a reference, showed a good linear relationship through the origin over the range $1 \times 10^{-6} \mathrm{M}-5 \times 10^{-6} \mathrm{M}\left(0.41 \mu \mathrm{g} \mathrm{ml}^{-1}-\right.$ $2.04 \mu \mathrm{g} \mathrm{m}^{-1}$ ) of berberine. This, however, happened only when the formation of ternary ion associates occurred with the coexistence of quinidine. The molar absorptivities of berberine were $6.4 \times 10^{4} 1 \mathrm{~mol}^{-1} \mathrm{~cm}^{-1}$ at $605 \mathrm{~nm}$ for $\mathrm{BPB}, 5.3 \times 10^{4}, 605 \mathrm{~nm}$ for $\mathrm{BCPB}, 3 \times 10^{4}$, $633 \mathrm{~nm}$ for BCG and $3.5 \times 10^{4}, 625 \mathrm{~nm}$ for TBPB. The relative standard deviations for ten determinations of $2 \times 10^{-6} \mathrm{M}$ berberine were $0.9 \%$ for BPB, $1.17 \%$, BCPB, $0.71 \%, \mathrm{BCG}$ and $1.31 \%$ for TBPB.

\section{Interferences}

To a solution containing $2 \times 10^{-6} \mathrm{M}$ berberine were added various amounts of foreign compounds such as procaine, ephedrine, methylephedrine, papaverine (aromatic amines), triethylamine, trimethylamine (aliphatic amines), tetraethylammonium, neostigmine and acrinol (quaternary ammonium salts). Their interferences were then investigated by the standard procedure described above. As shown in Table 2, the optimum $\mathrm{pH}$ ranges with quinidine were shifted to more alkaline media in all cases, compared with quinine coexistence. Accordingly, interference from amines can be eliminated, since a number of amines are present as base forms in alkaline media. Table 3 shows the effect of foreign substances and the tolerable limits. Though BCPB and BCG were excellent for a selective determination of berberine,

\begin{tabular}{|c|c|c|c|c|c|c|c|c|}
\hline \multirow{2}{*}{ Substance added } & \multicolumn{2}{|c|}{ BPB (pH 7.75) } & \multicolumn{2}{|c|}{ ВСРВ (8.2) } & \multicolumn{2}{|c|}{ BCG (8.5) } & \multicolumn{2}{|c|}{ TBPB $(10.0)$} \\
\hline & MR & Rec., \% & MR & Rec., \% & MR & Rec., \% & MR & Rec., $\%$ \\
\hline Procaine & 10 & 101.0 & 50 & 102.8 & 75 & 102.1 & 30 & 97.3 \\
\hline Ephedrine & 200 & 99.4 & 200 & 97.6 & 200 & 98.9 & 5 & 101.1 \\
\hline Methylephedrine & 50 & 101.9 & 200 & 101.5 & 10 & 102.8 & 10 & 97.5 \\
\hline Papaverine & 30 & 100.6 & 50 & 102.3 & 125 & 101.7 & 10 & 100.5 \\
\hline Eserine & 10 & 102.3 & 15 & 102.9 & 10 & 102.8 & 5 & 99.8 \\
\hline Dibucaine & 20 & 101.7 & 10 & 102.4 & 40 & 102.6 & 30 & 97.9 \\
\hline Diphenhydramine & 5 & 102.8 & 5 & 102.4 & 8 & 102.9 & 50 & 99.6 \\
\hline Chlorpheniramine & 3 & 102.7 & 4 & 102.4 & 10 & 101.7 & 10 & 102.2 \\
\hline Triethanolamine & 100 & 100.5 & 50 & 102.4 & 100 & 101.6 & 10 & 101.3 \\
\hline Triethylamine & 100 & 97.8 & 200 & 100.9 & 100 & 102.9 & 5 & 102.0 \\
\hline Trimethylamine & 200 & 99.8 & 200 & 98.9 & 200 & 100.9 & 1 & 97.7 \\
\hline Tetramethylammonium & 200 & 101.7 & 200 & 98.0 & 200 & 101.3 & 200 & 98.0 \\
\hline Tetraethylammonium & 50 & 102.7 & 100 & 102.5 & 10 & 102.2 & 1 & 101.1 \\
\hline Neostigmine & 30 & 102.9 & 30 & 102.3 & 10 & 102.1 & 0.5 & 100.1 \\
\hline Acrinol & 0.05 & 102.7 & 0.05 & 100.9 & 0.1 & 102.8 & 1 & 98.4 \\
\hline Sparteine & 0.05 & 101.4 & 0.1 & 102.3 & 0.1 & 101.3 & 0.01 & 98.7 \\
\hline
\end{tabular}
BCPB was more sensitive than BCG.

Table 3 Tolerance limits of foreign substances in the determination of $2 \times 10^{-6} \mathrm{M}$ berberine

MR: molar ratio; [substance added]/[berberine], [M]/[M]. 


\section{Extraction of berberine in Coptidis Rhizoma and Phel- lodendri Cortex}

A $1.0 \mathrm{~g}$ amount of Coptidis Rhizoma or Phellodendri Cortex was accurately weighed, and the sample defatted with $100 \mathrm{ml}$ of ether using Soxhlet's extractor for $2 \mathrm{~h}$. After removing the ether, berberine-type alkaloids were extracted with $100 \mathrm{ml}$ of ethanol for $10 \mathrm{hr}$. The alcoholic solution was concentrated to $10 \mathrm{ml}$ in a water bath. The sample solution was diluted to $100 \mathrm{ml}$ with distilled water after adding $3 \mathrm{ml}$ of $10 \%$ hydrochloric acid. Appropriate volumes of the solution were taken for a berberine determination.

\section{Determination of berberine in crude drugs}

Berberine, palmatine and coptisine are contained in crude drugs as berberine-type alkaloids, although the total amounts of palmatine and coptisine are extremely small compared with the berberine content.

Therefore, calibration graphs were prepared for berberine, palmatine and coptisine by both the TBPE method $^{4}$ and the BCPB-quinidine system proposed above. The molar absorptivities obtained by the TBPE method were $9.5 \times 10^{4} \mathrm{l} \mathrm{mol}^{-1} \mathrm{~cm}^{-1}$ for berberine, $7.9 \times 10^{4}$, for coptisine and $7.2 \times 10^{4}$, for palmatine. However, trace amounts $\left(10^{-7} \mathrm{M}\right.$ order $)$ of palmatine and coptisine could not be extracted in the BCPB-quinidine system. The samples were analyzed according to a standard addition method. In order to test the accuracy, known amounts of the berberine standard solution were added to the sample solutions and recovery tests performed. Recoveries were 95-99\%. The results given in Table 4 show an approximate agreement with the values obtained by ion-pair high performance liquid chromatography. ${ }^{8}$ In all cases, the TBPE method showed large contents compared with those obtained by the BCPBquinidine method. It is assumed that all berberine-type alkaloids and other alkaloids contained in crude drugs were detected using the TBPE method.
Table 4 Determination of berberine in crude drugs

\begin{tabular}{|c|c|c|c|}
\hline \multirow[b]{2}{*}{ Sample } & \multicolumn{3}{|c|}{ Content, ${ }^{\mathrm{b}} \%$} \\
\hline & & TBPE method ${ }^{a}$ & $\begin{array}{l}\text { BCPB-Quinidine } \\
\text { method }^{\mathrm{a}}\end{array}$ \\
\hline Coptidis Rhizoma & & 8.32 & 7.54 \\
\hline \multirow[t]{3}{*}{ Rhellodendri Cortex } & 1 & 4.97 & 4.39 \\
\hline & 2 & 4.96 & 4.34 \\
\hline & 3 & 4.50 & 3.73 \\
\hline
\end{tabular}

a. Average for three determinations by standard addition method.

b. The contents are shown as percentage per dried crude drugs.

In conclusion, the formation of ternary complexes in the presence of dibasic acid dyes $\left(\mathrm{A}^{2-}\right)$ and quinidine is available to determine the berberine content in crude drugs selectively and sensitively.

\section{References}

1. M. E. Auerbach, Ind. Eng. Chem., Anal. Ed., 15, 492 (1943).

2. K. Kaneda and M. Keida, Eisei Kagaku, 22, 370 (1976).

3. G. V. Scott, Anal. Chem., 40, 768 (1968).

4. T. Sakai, Dojin News, 30, 1 (1984).

5. T. Sakai, I. Hara and M. Tsubouchi, Chem. Pharm. Bull., 24, 1254 (1976).

6. T. Sakai, Analyst [London], 108, 608 (1983).

7. Society of Japanese Pharmacopoeia ed., "Nihon Yakkyokuho Tyukai (Commentary of the Japanese Pharmacopoeia XI, in Japanese)", C-316, Hirokawa Publishing Co., Tokyo, 1986.

8. K. Sagara, Y. Ito, M. Ojima, T. Oshima, T. Yoshida and H. Itokawa, Brnseki Kagaku, 35, 326 (1986).

(Received August 6, 1990) (Accepted November 28, 1990) 